\section{Prevention of blindness in leprosy and the role of the Vision 2020 Programme}

\begin{abstract}
Leprosy control programmes are highly successful. As a result, leprosy control will be more and more integrated into the general health services. The existing vertical, specialized control programmes will be dismantled. Eye complications in leprosy have decreased. This is a result of earlier diagnosis and highly effective multidrug treatment (MDT) of leprosy, combined with timely treatment of secondary nerve damage by steroids. Most ocular morbidity is now found among elderly and disabled leprosy patients who were diagnosed before effective MDT treatment became available. Many of these patients live in leprosy settlements. Age-related cataract has become the leading cause of blindness in leprosy. The second cause of blindness is corneal opacification, mainly as a result of neglected exposure keratitis and corneal anaesthesia. The miotic pupils in late multibacillary leprosy, in combination with small central lens opacities, may also lead to blindness. The Vision 2020 Initiative prioritises cataract surgery. Leprosy patients should be actively included. Disabled leprosy patients can also benefit from screening programmes for refractive errors and the provision of spectacles and low vision aids. Determining the most feasible surgical methods for lagophthalmos surgery remains a challenge. For all health and eye care staff, training in leprosy and its eye complications is needed, as well as a change in attitude towards leprosy patients. Staff must be prepared to welcome them in the general health services.
\end{abstract}

Eye (2005) 19, 1099-1105. doi:10.1038/sj.eye.6701984

Keywords: leprosy; blindness; Vision 2020
M Hogeweg ${ }^{1}$ and JEE Keunen ${ }^{2}$

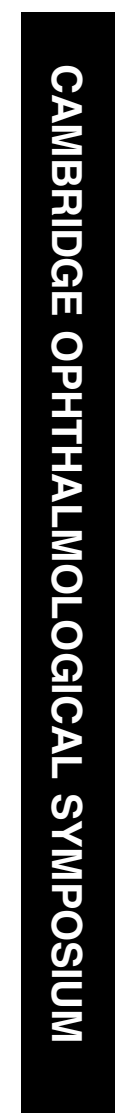

\section{Introduction}

The World Health Organization (WHO) aims at eliminating leprosy as a public health problem by 2005 . This goal has been arbitrarily defined as 'a prevalence rate of active leprosy cases, in need of anti-M leprae treatment, of less than $1 / 10000$ in any country'. Great progress in leprosy control has been made over the past 20 years. Before the introduction of the multiple drug treatment (MDT, a fixed duration combination therapy of dapsone, rifampicin, and clofazimine) in 1982, more than 12 million leprosy patients were on the treatment registers. In 2003, only 513798 new patients were detected for treatment worldwide. ${ }^{1}$ The great majority of these patients were found in India, Brazil, Indonesia, Nepal, and Mozambique. Leprosy has been eliminated from 108 countries out of 122, where leprosy was considered a public health problem in 1985. This impressive decrease in the number of patients is primarily attributed to the shortening of treatment duration with MDT (6-12 months, as compared to the often lifelong treatment with dapsone before MDT was introduced) and the updating of the registers. The global number of new cases detected annually has remained rather stable since the introduction of MDT, around 500000 600000 new cases per year. Compared to the many millions of people with HIV/Aids, TB, and malaria, the current number of patients with active leprosy is low. However, not included in the prevalence and case-detection statistics are the more than 12 million patients released from treatment, who do not form a risk of spreading the infection any longer. An unknown but considerable proportion of the patients are left with the ravages of end-stage leprosy: severely damaged hands, feet, and also - which is often not realized - eyes. These complications occur in particular in the elderly
${ }^{1}$ Department of Opthalmology, Leiden University Medical Centre,

${ }^{2}$ Nijmegen University Medical Centre, Nijmegen, The Netherlands

Correspondence: JEE Keunen, Institute of Ophthalmology, Nijmegen University Medical Centre, PO Box 9101, 6500 HB Nijmegen, The Netherlands Tel: + 3142 3613138;

Fax: + 31243540522.

E-mail: j.keunen@ ohk.umen.nl

Received: 28 April 2005 Accepted: 2 May 2005 Leiden, The Netherlands 
patients with a long history of disease, who were already diagnosed with leprosy before the introduction of MDT, and who initially were treated with dapsone monotherapy. These patients often live in leprosy settlements, leprosaria, of beggar colonies, in abject poverty. Stigma against patients with visible deformities is still high in many places. For them accessing the general health services can be quite difficult.

Nowadays, leprosy not being a major public health problem anymore, the vertical leprosy programmes under the Ministries of Health are gradually being dismantled and antileprosy treatment will be fully integrated within the general health services. General health services, including eye care services, will become fully responsible. However, whether the Prevention of Blindness (PBL) programmes and the eye care services are fully prepared for their new task, remains to be seen. This paper summarizes the current causes of blindness in leprosy and will discuss the opportunities the Vision 2020 Initiative offers, to preserve eye sight in leprosy.

\section{Blindness and eye complications in leprosy}

Although leprosy control has been a public health success over the past decades, leprosy patients still suffer from avoidable blindness. Blindness for leprosy patients is really a disaster. They completely depend on eye sight to protect their often anaesthetic limbs from injuries and burns. An estimated 200000-300 000 leprosy patients are blind. Of all causes of blindness $0.5-1 \%$ are directly related to leprosy, and another $1-2 \%$ due to co-morbidity with general eye diseases, in particular age-related cataract. $^{2}$ Eye complication in leprosy mainly occur in multibacillary $(\mathrm{MB})$ patients. Even more so since the definition of $\mathrm{MB}$ disease has been widened: many patients formerly classified as paucibacillary (PB) borderline tuberculoid patients (BT) now are included in the MB group. When considering eye complications and blindness in leprosy, it is important to distinguish between the preMDT, now mainly elderly cohort of patients with a long history of disease and the generally younger patients, with a shorter history of disease. The latter have been treated with MDT only, and show considerably less ocular complications. Prevalence of reported eye complications and blindness in leprosy also strongly depends on the method of examination, the kind of complications included and the definition of blindness used.

Some examples of studies published since 2000 are summarized in Table 1. The LOSOL study on eye disease in $691 \mathrm{MB}$ leprosy patients at baseline shows an ageadjusted prevalence of blindness of $2.8 \%(\mathrm{VA}<0.1){ }^{3}$ The figure for India was $1.6 \%$, the Philippines $1.3 \%$, and Ethiopia 5.5\%. The Indian Cohort study reported $0.84 \%$ blindness $(\mathrm{VA}<0.05)$ in 238 new MB patient at baseline. ${ }^{4}$ This is comparable to the general estimated prevalence of blindness in India. Four recent larger studies on elderly patients with long histories of leprosy, mostly living in leprosy settlements, all indicate that blindness in such patients is much higher, even today. ${ }^{5-8}$ If blindness among the general population above 50 years in developing countries is roughly taken as $5 \%(\mathrm{VA}<0.1)$, these data show that blindness among leprosy patients is at least $50 \%$ higher in a country like S Korea, with welldeveloped health services, free for leprosy patients, and two to three times higher in leprosy settlements in Nigeria and China. In China alone, there may be as many as 40000 blind, among the approximately 300000 currently living patients who have suffered from leprosy. Two recent and comparable smaller studies from Pakistan $^{9}(n=143)$ and Nepal $^{10}(n=58)$ report $11 \%$ and $9 \%$ of blindness, respectively.

Risk of death in blind leprosy patients is 4.8-fold in excess of nonblind same age peers. ${ }^{11}$ Point prevalence surveys tend to underestimate blindness, as many blind patients may have prematurely died.

In S Korea ${ }^{5} 23 / 114$ (14.7\%) of treated leprosy patients, who had initially been free of complications, developed new and potentially blinding eye lesions over an 11-year period. Blindness in the better eye visual acuity $(\mathrm{VA}<0.1)$ developed in $15 / 263(5.7 \%)$ of the surviving patients.

Many patients are incurably blind. It is important to identify those blind patients who can still be treated, for instance by cataract extraction.

\section{Cataract}

Cataract is the leading cause of blindness among leprosy patients and can be responsible for as many as 40-50\% of all cases (Figure 1). This includes those who have completed MDT. The majority of cataracts is assumed to be simple age-related, but it has been shown repeatedly that cataract is more common in MB than in PB patients. Some cataracts may be due to long-term steroid use in severe or recurrent leprosy immune reactions. The role of chronic uveitis in unclear, but may triple the risk of cataract. $^{12}$

The quoted studies all illustrate the high prevalence of cataract as a cause of blindness or severe visual impairment. With increased life expectancy, also for leprosy patients, numbers of cataract blind can be expected to further increase.

In the 11 years follow-up study in S Korea, cataract caused $87 \%$ of the incident blindness. Cataract surgical coverage (defined as the number of patients who had cataract surgery in one or both eyes, divided by the total number of patients with cataract and after cataract 
Table 1 Recent studies on prevalence and causes of blindness in leprosy

\begin{tabular}{|c|c|c|c|c|c|}
\hline $\begin{array}{l}\text { Country } \\
\text { (year of } \\
\text { publication) }\end{array}$ & Study design & No. of patients & $\begin{array}{l}\text { Age, duration of } \\
\text { leprosy }\end{array}$ & $\begin{array}{l}\text { Prevalence and main causes of } \\
\text { bilateral blindness in } \%\end{array}$ & Eye lesions \% \\
\hline $\begin{array}{l}\text { India, the } \\
\text { Philippines, } \\
\text { Ethiopia } \\
(2002)^{3}\end{array}$ & $\begin{array}{l}\text { Multicentre study } \\
\text { of MB patients at } \\
\text { baseline (LOSOL) }\end{array}$ & 691 & $\begin{array}{l}\text { Mean age: } 35 \text { years } \\
\text { mean history of } \\
\text { leprosy: } 1.9 \text { years }\end{array}$ & $\begin{array}{l}2.8 \%(\mathrm{VA}<0.1) 50 \% \text { due to } \\
\text { cataract }\end{array}$ & $\begin{array}{l}\text { lagophthalmos: } 3.3 \% \\
\text { trichiasis: } 1.0 \% \\
\text { corneal scar: } 8.1 \% \\
\text { uveal conditions: } 4.1 \% \\
\text { cataract (VA<6/18): } 5.3 \%\end{array}$ \\
\hline India $(2002)^{4}$ & $\begin{array}{l}\text { Newly enrolled } \\
\text { MB patients in } \\
\text { active case finding } \\
\text { programme, at } \\
\text { baseline }\end{array}$ & 238 & $\begin{array}{l}\text { Mean age: } 41 \text { years } \\
\text { mean history of } \\
\text { leprosy: } 3.3 \text { years }\end{array}$ & $\begin{array}{l}0.84 \%(\mathrm{VA}<0.05) \\
4.6 \% \text { blind eyes } \\
\text { causes not reported }\end{array}$ & $\begin{array}{l}\text { lagophthalmos: } 4.2 \% \\
\text { trichiasis: } 0.8 \% \\
\text { corneal scar: } 10.5 \% \\
\text { uveal conditions: } 6.7 \% \\
\text { cataract (VA<6/18): } 12.6 \%\end{array}$ \\
\hline $\begin{array}{l}\text { S Korea } \\
(2000)^{5}\end{array}$ & $\begin{array}{l}11 \text { years follow-up } \\
\text { study in eight } \\
\text { resettlement } \\
\text { leprosy villages }\end{array}$ & 270 & $\begin{array}{l}\text { Mean age: } 64 \text { years } \\
\text { mean history of } \\
\text { leprosy: } 55 \text { years }\end{array}$ & $\begin{array}{l}8.1 \%(\mathrm{VA}<0.1) \\
11.6 \% \text { of patients developed } \\
\text { blindness in one or both eyes } \\
\text { in an } 11 \text { years period. } \\
\text { Cataract caused } 87 \% \text { of the } \\
\text { incident blindness }\end{array}$ & $\begin{array}{l}\text { Data not comparable; } 14.7 \% \\
\text { of those initially free of } \\
\text { lesions developed new } \\
\text { keratitis, synechiae or } \\
\text { lagophthalmos in an } \\
11 \text { years period }\end{array}$ \\
\hline $\begin{array}{l}\text { Cameroon } \\
(2001)^{6}\end{array}$ & $\begin{array}{l}\text { Survey in five } \\
\text { leprosaria }\end{array}$ & 218 & $\begin{array}{l}\text { Mean age: } 59 \text { years; } \\
\text { duration not } \\
\text { reported }\end{array}$ & $\begin{array}{l}38.3 \% \text { blind eyes (VA } 0.1 \text { ) } \\
\text { data on bilateral blindness } \\
\text { not reported }\end{array}$ & $\begin{array}{l}\text { lagophthalmos: } 10.1 \% \\
\text { trichiasis: } 3.2 \% \\
\text { corneal scar: } 36 \% \\
\text { uveal conditions: } 17.3 \% \\
\text { cataract: } 32.3 \%\end{array}$ \\
\hline $\begin{array}{l}\text { Nigeria } \\
(2003)^{7}\end{array}$ & $\begin{array}{l}\text { Survey in eight } \\
\text { leprosy villages }\end{array}$ & $\begin{array}{l}480(>30 \\
\text { years })\end{array}$ & $\begin{array}{l}\text { Mean age: } 50-59 \\
\text { years } \\
\text { history of leprosy } \\
>10 \text { years in } 68 \%\end{array}$ & $\begin{array}{l}10.4 \%(\mathrm{VA}<0.05) \\
17.9 \% \text { (VA } \leq 0.1) \\
46 \% \text { due to cataract } \\
40 \% \text { due to corneal scarring } \\
\text { (nontrachomatous } 28 \% ; \\
\text { trachomatous } 12 \%\end{array}$ & $\begin{array}{l}\text { lagophthalmos: } 12.6 \% \\
\text { trichiasis: } 9.3 \% \\
\text { corneal scar: } 15.5 \% \\
\text { uveal conditions: } 2.2 \% \\
\text { cataract: } 33.4 \%\end{array}$ \\
\hline $\begin{array}{l}\text { China, } \\
\text { Taixin city } \\
(2003)^{8}\end{array}$ & $\begin{array}{l}\text { 'Whole leprosy } \\
\text { patient survey' }\end{array}$ & $\begin{array}{c}1045 \\
\text { out patients }\end{array}$ & $\begin{array}{l}\text { Mean age: } 45 \text { years } \\
\text { mean duration of } \\
\text { leprosy: } 29 \text { years }\end{array}$ & $\begin{array}{l}7.7 \% \text { (VA }<0.05) \text { (inpatients } \\
12.6 \% \text {; outpatients } 5.7 \% \\
51 \% \text { due to corneal scarring; } \\
21 \% \text { due to cataract; }\end{array}$ & Data not comparable \\
\hline
\end{tabular}

surgery) in the same setting was $78.3 \%(36 / 46)$ for patients with a cutoff point of VA $<0.1$ and $55.4 \%(36 / 65)$ for patients with a cutoff point of $\mathrm{VA}<0.3 .{ }^{13}$ It should be kept in mind that these percentages are for a wellserviced population with good access to free eye care. A similar assessment of cataract surgical coverage among inhabitants of leprosy settlements in Nigeria was $44 \%$ $(23 / 52$ patients, cutoff point $\mathrm{VA}<0.05){ }^{12}$

Reasons for not having had surgery in the Korean study $(\mathrm{VA}<0.3)$ were 'cataract not mature' in 28/48 (58\%) patients, and 'no felt need' in 9/48 (19\%) patients. In Nigeria, the main reasons for not having had surgery were 'costs' in 38/107 (36\%), 'no service available' in 26 (24\%), 'no felt need' in 19 (18\%) (mainly unilateral cataract), 'unawareness of treatment' in $10(9 \%)$, and fear in nine $(8 \%)$ of patients. ${ }^{14}$

Eye care services are not likely to consider leprosy patients their priority. Screening and outreach are rarely provided to these communities. Some eye departments are unwilling to admit obvious patients, because of stigma against leprosy.

\section{Outcome of cataract surgery in leprosy patients}

Only few data are available. Older studies report on intracapsular cataract extraction (ICCE) without intraocular lens (IOL) implantation, which has become less relevant. A 1998 study from Brazil ${ }^{15}$ has reported results of extracapsular (ECCE) IOL surgery in 70 eyes. In all, 22 eyes (31.4\%) showed leprosy lesions, such as iris atrophy, synechiae and miosis. VA improved in 65/70 eyes (93\%). 46 eyes (65.7\%) achieved a postoperative $\mathrm{VA} \geq 0.5$ and five $(7 \%)$ had a $\mathrm{VA}<0.1$, as result of various retinal conditions. Meanwhile, IOL surgery has become routine, where facilities are available. This is of extra advantage for leprosy patients because the heavy aphakic spectacles will not fit on collapsed noses and 


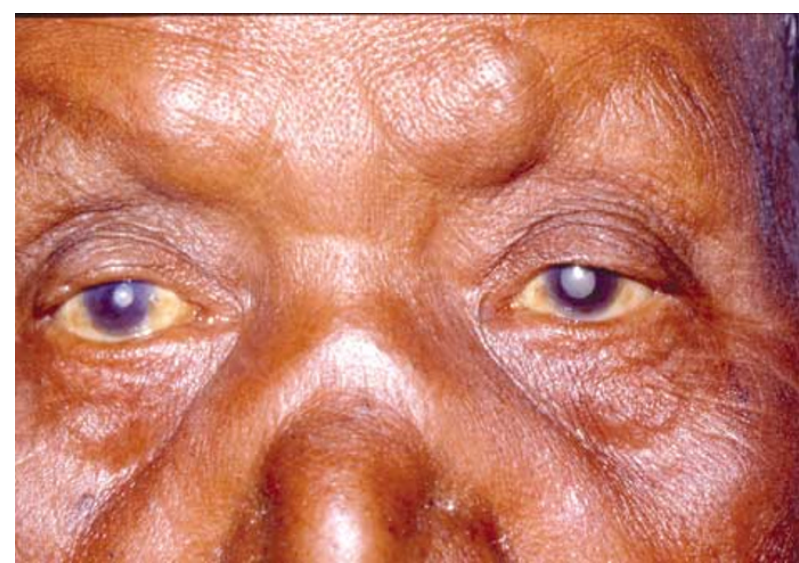

Figure 1 Bilateral mature cataract in MB patient. Note complete madarosis of brows and lashes and collapse of nose.

may be difficult to handle for patients with severely damaged hands.

In merely age-related cataract, being the majority, results should be more or less equal to surgery in the general population. Eyes with lesions due to leprosy, such as miotic, distorted and nondilating pupils, iris atrophy, posterior synechiae, anterior staphyloma or corneal scarring from exposure keratitis, will make cataract surgery challenging and results uncertain. The Korean survey among resettlement patients showed a presenting postoperative VA $>6 / 24$ in 23/36 (69\%) pseudophakic eyes and VA $<0.1$ in five $(14 \%) .{ }^{13}$ With best correction this improved to $30(83 \%)$ with a VA $>6 / 24$ and only one $(2.8 \%)$ with a VA $<0.1$. In Nigeria, $7 / 39$ $(18 \%)$ of the operated eyes of patients in the leprosy villages were blind $(\mathrm{VA}<0.05)$, rising to $10(25.6 \%)$ if the cutoff point for blindness is taken as VA $<0.1 .{ }^{14}$ Only three eyes $(7.7 \%)$ were pseudophakic of which one eye was blind. All other eyes were aphakic. VA was taken with $S+10$. Further studies on the outcome of IOL implant surgery in eyes with intraocular leprosy lesions are still needed. ${ }^{16}$

\section{Lagophthalmos and corneal disease}

Corneal scarring forms the second cause of blindness in leprosy (Figures 2 and 3). This is either caused by exposure keratitis in lagophthalmos, possibly compounded by corneal anaesthesia, caused by trichiasis, or the result of trauma and corneal ulceration. Often these conditions lead to unilateral blindness or visual impairment, rather than bilateral blindness.

Facial nerve damage and subsequent lagophthalmos are mainly caused by Type 1 leprosy immune reactions in the face, often in combination with red and raised facial patches. The largest risk for such reactions is either

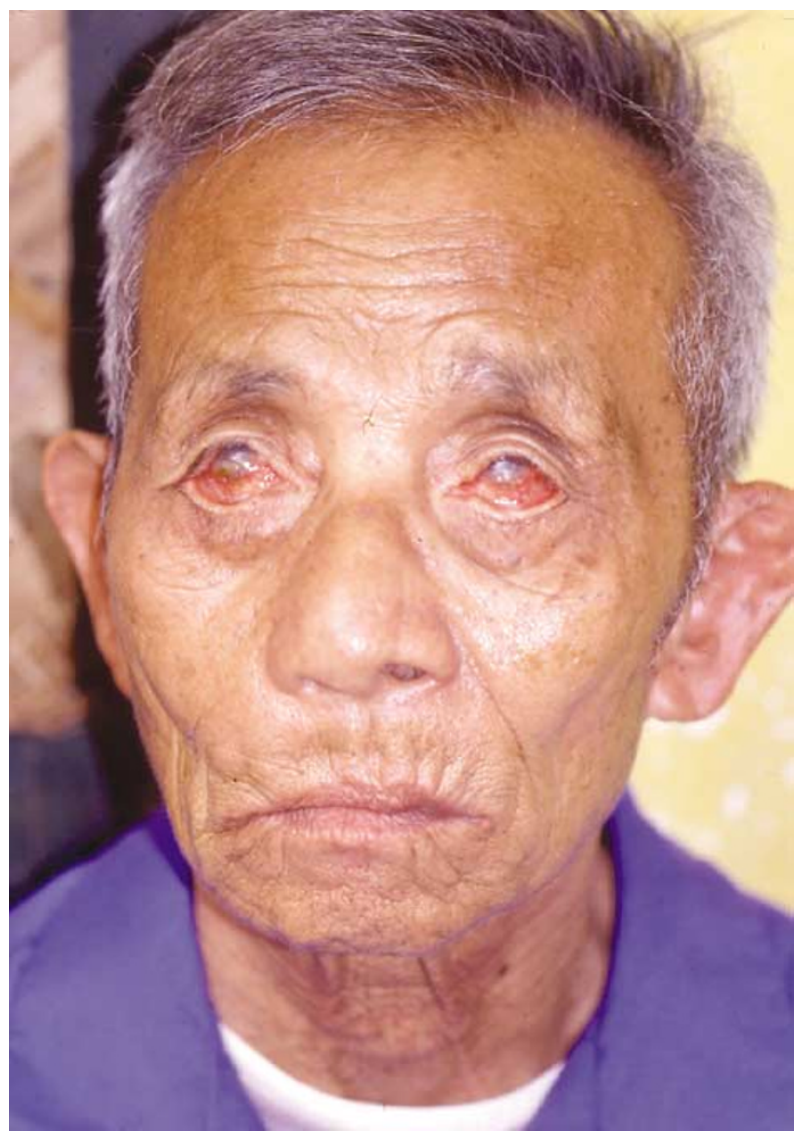

Figure 2 Leprosy patient blinded by exposure keratitis in severe bilateral lagophthalmos.

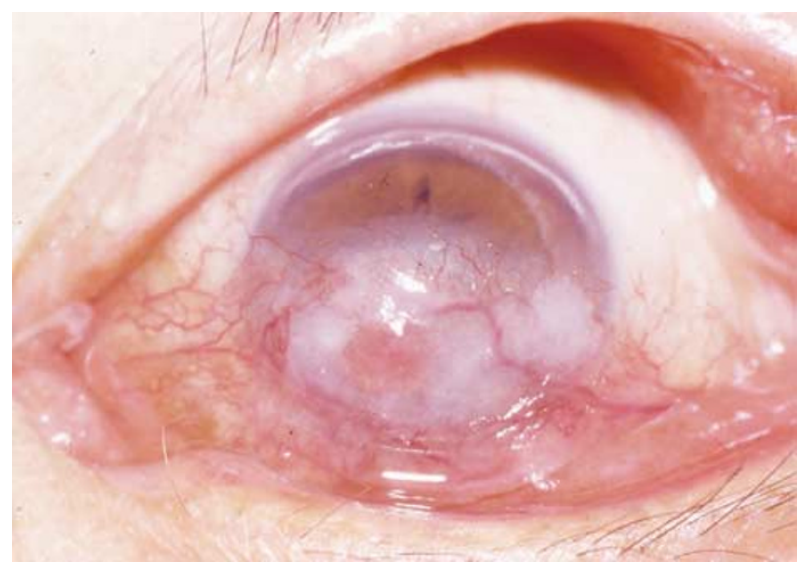

Figure 3 Detail of Figure 2: Left eye: severe exposure keratitis.

before diagnosis of leprosy, or during the first 6-12 months of antileprosy treatment. ${ }^{17}$ After completion of MDT, the risk of new facial nerve damage is small. The aetiology of lagophthalmos in polar lepromatous leprosy is probably different. It appears late and is mostly bilateral. 
The LOSOL study reported lagophthalmos in 3.3\% of newly diagnosed MB leprosy patients and an incidence of $2 \%$ during 2 years of MDT. The Indian Cohort Study reported lagophthalmos in either eye in $4.2 \%$ of the MB patients at intake. Prevalence of lagophthalmos among patients living in settlements is much higher. Among the inmates of leprosaria in Cameroon lagophthalmos was noted in $10 \%$ of patients; $36 \%$ of the eyes had corneal scars or leukoma. In leprosy villages in Nigeria, lagophthalmos was also common and seen in $14.4 \%$ of patients, $12.6 \%$ of eyes. ${ }^{18}$ In $5.6 \%$ of patients (27 eyes), lagophthalmos was severe with a lid gap $>6 \mathrm{~mm}$. In $14 / 50(28 \%)$ of patients, the cause of blindness was due to nontrachomatous corneal scarring, second after cataract. Another six patients (12\%) were blind due to trachomatous scarring, as trachoma is highly endemic in this part of Nigeria. In China, the main cause of blindness was reported to be corneal disease: $41 / 80$ patients $(51 \%)$. All these patients in settlements have a long history of leprosy. The patient's delay before diagnosis of leprosy may have been long, treatment with dapsone monotherapy was less effective, and leprosy reactions may not have been treated in time.

Surprisingly, there are only very few studies on the results of the various types of surgery for lagophthalmos. ${ }^{19}$ Simple temporal tarsorraphia is the most commonly performed procedure but, if extensive, is a cosmetic blemish. Moreover it does not correct the often coexisting ectropion. In addition, the resulting loss of temporal visual field is much disliked by patients. Other static lid procedures are used less. Often a considerable lid gap remains after lid surgery. Cumbersome complaints of watering and burning sensation continue. In S Korea, 12/41 (29\%) eyes still showed a lid gap $>5 \mathrm{~mm}$ after lid surgery for lagophthalmos (primarily a temporal tarsal strip procedure) ${ }^{20}$ In fact, these eyes still needed additional surgery. A problem in evaluating postoperative results of lagophthalmos surgery is that the preoperative condition is often unknown. Indications for surgery have not been universally agreed. It is difficult to build up sufficiently large series for evaluation.

Surgical coverage for lagophthalmos is low: 34/60 (57\%) lagophthalmos eyes had undergone lid surgery in S Korea. ${ }^{20}$ Of 25 patients interviewed, seven (28\%) were not satisfied with the result. In Nigeria, 20/47 (43\%) eyes in need of lid surgery had been operated. ${ }^{18}$ Patient satisfaction was not studied. Further research on indications and the best procedures, in terms of effectiveness, feasibility in field circumstances and acceptability by patients, is highly recommended.

Corneal scarring from exposure keratitis is generally avoidable because:
1. Reactive patches in the face and early lagophthalmos can be treated by systemic corticosteroids, as is usual in Type 1 immune reactions. This may prevent or limit facial nerve damage. ${ }^{21}$

2. Eyes with established lagophthalmos can be protected with sunglasses. Patients should receive health education and blinking instruction and eyes should be regularly checked. Eyes with good corneal sensitivity and mild lagophthalmos will usually not develop exposure keratitis.

3. Eyes with lid gaps $>5 \mathrm{~mm}$ and corneal exposure are at risk of progressive exposure keratitis and corneal injury, in particular in combination with corneal anaesthesia. These eyes should undergo lid surgery for protection.

\section{Other causes of blindness in leprosy}

In the past, severe iritis and sclero-uveitis with secondary glaucoma were important causes of blindness in MB patients, who developed severe Type 2 leprosy immune reactions. Since the introduction of clofazimine as part of MB MDT, these severe Type 2 reactions have become less common and subsequently severe iritis and sclero-uveitis have decreased. Chronic uveitis, with constricted to extremely miotic pupils, is still seen in patients with a long history of MB leprosy. It may develop or progress even long after completion of MDT. ${ }^{5}$ Treatment is not satisfactory. Pupils can hardly be dilated, due to the accompanying atrophy of the iris dilator muscle and synechiae formation. Combination with centrally located lens opacities may lead to blindness. In future, early diagnosis of leprosy and timely treatment with MDT will hopefully prevent this late complication.

\section{Vision 2020 and PBL in leprosy}

Vision 2020, the Right to Sight, in conjunction with the $\mathrm{WHO}$, is an initiative to eliminate avoidable blindness by the year 2020. It focuses primarily on combating the leading causes of world blindness: cataract, trachoma, onchocerciasis, childhood blindness, and refractive errors and low vision. Vision 2020 considers an increase in volume and quality of cataract surgery as the first priority.

Ocular leprosy itself is not a target of Vision 2020 but, as cataract is a main cause of blindness in leprosy, it becomes important that positive action is taken by Vision 2020 and national PBL Programmes to include these patients for cataract surgery. As responsibility for treatment of leprosy will be integrated into the general health services, the eye care services should take their 
own responsibility. Therefore, annual screening and inclusion of leprosy settlements, leprosaria and leprosy colonies in regular outreach programmes, is highly recommended. Apart from free surgery, free transport and food may have to be provided, also for the guardian. Charities and service organizations may need to be approached for extra funding.

The problem of stigma, among the general population but also among health care staff, has to be addressed. This often prevents smooth admission of these patients in a general hospital. Day surgery can offer a solution, provided reliable postoperative control is arranged. Alternatively, surgery can be provided locally, if sufficient after care can be guaranteed.

In trachoma endemic areas, leprosy patients, in particular women, should be included in screening programmes for trachoma and receive lid surgery for correction of entropion and trichiasis. For example, among 470 patients living in leprosy settlements in Nigeria, 29 eyes had been operated for trichiasis vs 89 eyes still in need of trichiasis surgery, a surgical coverage of only $24.6 \% .^{18}$

The situation of onchocerciasis is probably the same for leprosy patients as for the general population. Leprosy settlements should of course be included in the ivermectine distribution programmes. Children of leprosy patients, living in the poorest communities, should be actively included in regular immunization and Vitamin A distribution programmes.

Refractive errors and need for spectacle correction among leprosy patients have not been studied. Aphakic leprosy patients may long have lost or broken their aphakic glasses and may be unable to replace them. Immobile literate leprosy patients may be in desperate need for reading glasses and also others may need presbyopic glasses for any nearby work. Some of these patients could profit from low vision aids. This certainly is a completely neglected field.

\section{Conclusions}

Today, risk of blindness and severe visual impairment in new leprosy patients has been greatly reduced, by early diagnosis of leprosy, effective treatment and timely treatment of leprosy immune reactions. In contrast, prevalence of blindness among the fairly large group of disabled elderly ex-patients, may be as much as $2-3$ times higher than in the elderly general population. As much as $40-50 \%$ of this blindness is caused by cataract and therefore avoidable. Under Vision 2020, positive action to operate this unfortunate group of people should be taken. The results of lagophthalmos surgery, in particular the most commonly used temporal tarsorraphia, are often unsatisfactory. Better techniques for field use should be tested and introduced. Refractive services are hardly available for disabled leprosy patients living in settlements. Integration of leprosy control programmes into the general health services is under way. This may possibly lead to less interest in, and less advocacy for, leprosy patients. Therefore, training of all health and eye care workers in the essentials of leprosy and its potential ocular complications becomes mandatory. Unjustified fear of leprosy should be allayed.

Thus, arrangements for eye examinations, refraction, and cataract and lagophthalmos surgery for leprosy patients need to be improved. More studies are needed on the barriers to access services, the outcomes of IOL surgery in complicated cataracts, and the most suitable technique for lagophthalmos surgery. Teaching on leprosy and its eye complications should be included in curricula and training manuals of all medical and ophthalmic staff.

Vision 2020 and a new drafting of National Prevention of Blindness programmes offer a great opportunity to include leprosy patients in the various aspects of the programme, also for countries that at present detect only few new cases of leprosy, and already have achieved 'elimination'. Such countries nevertheless may still harbour quite large numbers of leprosy patients, released from treatment, but left with the ravages of leprosy, and in urgent need of eye care.

\section{Acknowledgements}

The work was presented at the Cambridge Ophthalmological Symposium, St John's College Cambridge, 16-17 September 2004.

No proprietary interests nor research funding are involved.

\section{References}

1 Leprosy. Global situation 2004 www.who.int/topics/ leprosy/en/.

2 Courtright $\mathrm{P}$, Lewallen $\mathrm{S}$. Ocular manifestations of leprosy. In: Johnson G, Minassian D, Weale R, West S (eds) The Epidemiology of Eye Disease. Arnold: London, 2003, pp 306-317.

3 Courtright P, Daniel E, Sundarrao, Ravanes J, Mingister F, Belachew $\mathrm{M}$ et al. Eye disease in multibacillary leprosy patients at the time of their leprosy diagnosis: findings from the Longitudinal Study of Ocular Leprosy (LOSOL) in India, the Philippines and Ethiopia. Lepr Rev 2002; 73: 225-238.

4 Daniel E, Koshy S, Rao GS, Roa PS. Ocular complications in newly diagnosed borderline lepromatous and lepromatous leprosy patients: baseline profile of the Indian cohort. $\mathrm{Br} J$ Ophthalmol 2002; 86: 1336-1340.

5 Lewallen S, Tungpakorn NC, Kim SH, Courtright P. Progression of eye disease in 'cured' leprosy patients: 
implications for understanding the pathophysiology of ocular disease and for addressing eyecare needs. $\mathrm{Br} J$ Ophthalmol 2000; 84: 817-821.

6 Mvogo CE, Bella-Hiag AL, Ellong A, Achu JH, Nkeng PF. Ocular complications of leprosy in Cameroon. Acta Ophthalmol Scand 2001; 79: 31-33.

7 Mpyet C, Solomon AW. Prevalence and causes of blindness and low vision in leprosy patients of North-Eastern Nigeria. Br J Ophthalmol 2005; 89(4): 417-419.

8 Yan L, Zhang G, Zheng Z, Li W, Ye G. A survey of blindness and poor vision in leprosy patients. Chin Med J 2003; 116 682-684.

9 Khan T, Awan AA, Kazmi HS, Shah AA, Muhammad S, Muhammad S. Frequency of ocular complications of leprosy in institutionalised patients in NWFP Pakistan. J Ayub Med Coll Abbottabad 2002; 14: 29-33.

10 Nepal BP, Shrestha UD. Ocular findings in leprosy patients in Nepal in the era of multidrug therapy. Am J Ophthalmol 2004; 137: 888-892.

11 Courtright P, Kim SH, Lee HS, Lewallen S. Excess mortality associated with blindness in leprosy patients in Korea. Lepr Rev 1997; 68: 326-330.

12 Waddel KM, Saunderson PR. Is leprosy blindness avoidable? The effect of disease type, duration and treatment on eye damage from leprosy in Uganda. $\mathrm{Br} J$ Ophthalmol 1995; 79: 250-256.

13 Courtright $\mathrm{P}$, Lewallen S, Narong Tungpakorn, Beyong-Hee Cho et al. Cataract in leprosy patients: Cataract surgical coverage, barriers to acceptance of surgery and outcome of surgery in a population- based survey in Korea. Br J Ophthalmol 2001; 85: 643-647.

14 Caleb Mpyet. Cataract prevalence, surgical coverage and barriers to uptake of surgery among leprosy patients in NE Nigeria, Msc Thesis, LSHTM 2003.

15 Batistella GGG, Maarakoun M, Vilela de Castro A. Extracapusular cataract extraction and intra-ocular lens implantation in leprosy patients: visual outcome and complications. Indian J Leprosy 1998; 70: 5-11.

16 Waddell KM. Intra-ocular lens implantation for cataract following leprosy. Lepr Rev 1999; 70: 74-75.

17 Hogeweg M, Kiran KU, Suneetha S. The significance of facial patches and Type 1 reaction for the development of facial nerve damage in leprosy. A retrospective study among 1226 paucibacillary leprosy patients. Lepr Rev 1991; 62: 143-149.

18 Mpyet C, Hogeweg M. Lid surgery in persons affected with leprosy in North Eastern Nigeria: are the needs being met? Trop Doctor, in press.

19 Courtright $\mathrm{P}$, Lewallen S. Currant concepts in the surgical management of lagophthalmos in leprosy. Lepr Rev 1995; 66: 220-223.

20 Courtright P, Lewallen S, Tungpakorn N, Cho BH, Lim YK, Lee $\mathrm{HJ}$ et al. Lagophthalmos surgery in leprosy: findings from a population based study in Korea. Lepr Rev 2001; 72: 285-291.

21 Kiran KU, Hogeweg M, Suneetha S. Treatment of recent facial nerve damage with lagophthalmos, using a semi-standardized steroid regimen. Lepr Rev 1991; 62: 150-154. 